\title{
Aportes para el análisis de la rotación laboral tecno-informacional ${ }^{1}$
}

Elizabeth Lopez Bidone ${ }^{2}$

Recibido: 13/08/2019; Aceptado: 30/09/2019.

Cómo citar: Lopez Bidone, E. (2020) Aportes para el análisis de la rotación laboral tecno-
informacional. Revista Hipertextos, $8 \quad$ (13),
$\begin{aligned} & \text { https://doi.org/10.24215/23143924e013 } \\ & \text { pp. }\end{aligned}$

\section{Resumen}

Este artículo tiene por finalidad analizar las relaciones de producción que se entablan dentro del sector informático y los sucesos vinculados con rotación laboral. En esa línea, pueden observarse especificidades propias de los agentes que se encuentran trabajando en la industria y características concretas en las relaciones de producción que se entablan en el mismo. Por ello, se analizan algunas causas que conducen a la rotación laboral realizando un tratamiento del mismo ya no como suceso sino como proceso, pues se parte de la idea central que la rotación laboral constituye más que un hecho visible; dado que tras el suceso subyacen otras variables vinculadas con las relaciones capital- trabajo.

Palabras clave: Mercado Laboral, Tecnología Informática, Tecnología.

\begin{abstract}
In this article it is intended to analyze the production relations that are established within the computer sector and the events related to labor turnover. Along these lines, we can observe specific characteristics of the agents that are working in the industry and specific characteristics in the production relations that are established in it. For this reason, some causes that lead to labor rotation are analyzed, making a treatment of it no longer as an event but as a process, since it is
\end{abstract}

${ }^{1} \mathrm{El}$ presente artículo es parte del análisis realizado en el proyecto interdisciplinario: Caracterización y análisis del comportamiento del mercado laboral en el sector de Software y Servicios Informáticos de la ciudad de Tandil (2010-2017).

2 Docente de la Universidad Nacional del Centro de la Provincia de Buenos Aires, Facultad de Ciencias Humanas, Adjunta en el área de Economía. Investigadora en la planta estable del CEIPIL-CIC. Magister en Ciencias Sociales. Directora del Proyecto Interdisciplinario. Contacto: elopez@fch.unicen.edu.ar 
based on the central idea that labor rotation constitutes more than a visible fact; given that after the event there are other variables related to capital-labor relations.

Keywords: Labor Market, Information Technology, Technology.

\section{Resumo}

Neste artigo pretende-se analisar as relações de produção que se estabelecem no setor de informática e os eventos relacionados à rotatividade de mão de obra. Nessa linha, podemos observar características específicas dos agentes que atuam na indústria e características específicas nas relações de produção nela estabelecidas. Por essa razão, algumas causas que levam à rotação do trabalho são analisadas, fazendo com que o tratamento não seja mais como um evento, mas como um processo, pois se baseia na idéia central de que a rotação de trabalho constitui mais do que um fato visível; dado que após o evento existem outras variáveis relacionadas às relações capital-trabalho.

Palavras-chave: Mercado de Trabalho, Tecnologia da Informação, Tecnologia 


\section{Introducción}

Desde mediados del siglo XX, el sector informático ha sido clave en como motor de expansión de la productividad; pues originó y continúa provocando cambios profundos en las formas de organización social y económica. Puntualmente, su importancia reside en el caso de Argentina, en la expansión sostenida que ha tenido el sector en la últimas décadas en base a dos cuestiones: por una parte, en la producción de software que proporciona una plataforma para la innovación en todos los sectores; y por otra, en la conformación del mercado laboral dentro del sector como impulsor de puestos de trabajo.

Este artículo, tiene por finalidad analizar las relaciones de producción que se entablan dentro del sector y el impacto en los procesos de rotación laboral al menos en dos ámbitos: uno en las relaciones sociales de producción al interior de la empresa, y el otro, en los trabajadores y la ponderación de las capacidades intelectuales puestas en práctica en el proceso productivo.

$\mathrm{Al}$ respecto, puede señalarse que las capacidades diferenciales o capital simbólico específico vuelven a los poseedores del conocimiento técnico requerido para la economía del conocimiento el principal recurso económico y auténtico capital del tejido; dentro de un modo de producción que podemos denominar como capitalismo cognitivo, en el cual las prácticas económicas sobre las producciones de conocimiento están enmarcadas en el capitalismo globalizado de finales del siglo XX y principios del XXI (Blondeau, 1999; Boutang, 1999; Corsani, 2003; Rullani, 2000; Vercellone, 2000).

Por ello, el trabajo tecno-informacional viene definido por las actuales condiciones sistémicas. En ese sentido, debe aclararse que cuando hacemos referencia al trabajo tecno-informacional lo definimos como la prestación laboral en la cual existe una interdependencia entre trabajo humano y la utilización de medios informáticos-digitales, por tanto, supone que hablamos de una actividad laboral mediada por una estructura tecnológica especifica.

La complejidad propia del trabajo tecno- informacional, se traslada también a las relaciones sociales de producción impulsando algunos temas que giran en torno a las relaciones de empleo en sí mismas. Entre ellas, surge la rotación laboral, en parte, producto de la nueva organización de las actividades productivas.

Particularmente, en el presente artículo se parte de la idea central que la rotación laboral constituye más que el suceso visible; un proceso, pues tras el suceso subyacen otros hechos vinculados con las relaciones capital- trabajo. Bajo esta perspectiva, la rotación laboral se organiza como una figura más 
elaborada, más sostenida, y dependiente de relaciones en permanente tensión. En función de esto, todo orden está enlazado con otras variables de funcionamiento diverso y dinámico que en conjunción estructuran una complejidad que no se puede observar solamente en acciones puntuales.

Así, el tránsito hacia la rotación laboral puede ser pensado como un movimiento crítico que conlleva transformaciones en el nivel del sujeto y de la empresa. Las transformaciones más significativas de este pasaje se dan en las dimensiones de las nuevas medidas de tiempo/espacio, las nuevas relaciones en producción/capital/trabajo, las nuevas configuraciones del conflicto-social.

Estas transmutaciones, surgen actualmente derivadas del debilitamiento progresivo, en su contenido conceptual y operativo, de los antiguos marcos de referencia cargados de seguridad, confianza, previsibilidad, durabilidad; que han dado paso, a escenarios que comprometen las experiencias íntimas del sujeto y los compromisos institucionales del sistema, en realidades transitorias.

En ese sentido, son las instancias colectivas de la seguridad del capitalismo las que han sido transformadas y trastocadas, un ejemplo de ello se encuentra en las formas de organización laboral bajo modalidades de desregulación de la relación ocupacional y contractual; cuestión que de hecho, ha debilitado las seguridades del trabajador en las formas de inserción, participación, duración y desvinculación, y en consecuencia en su propia historia laboral.

A modo de ejemplificar las nuevas dinámicas en el ámbito tecno-productivo, en el transcurso del presente artículo se realizará un análisis del comportamiento y tendencias del mercado laboral del sector de Servicios Informáticos en las empresas que forman parte de la Cámara de Empresas del Polo Informático Tandil (CEPIT).

Resta una observación introductoria. Y es relativa a la metodología seguida en el trabajo de campo. Esta investigación se ha realizado bajo un análisis de estudio de caso en el cual se han utilizado tanto metodología cuantitativa, a partir de una muestra probabilística; como también, metodología cualitativa en las entrevistas en profundidad.

$\mathrm{Al}$ respecto, puede señalarse que en una primera etapa, de tipo cualitativa, se recolectó la información sobre la base del diseño de tres entrevistas en profundidad semi-estructuradas. El criterio utilizado fue el relevar la opinión de algunos actores dentro del sistema local de innovación, por ello se realizó a un gestor de una de las empresas incluidas en la CEPIT, el segundo término se entrevistó a un gestor de la asociación gremial informática de Tandil y por ultimo a un profesional informático. 
En una segunda fase de carácter cuantitativo, se realizó a partir de cuestionarios estandarizados con el método de encuesta, con una muestra aleatoria de 46 trabajadores que se hallan incluidos en la Población Económicamente Activa pertenecientes a empresas de la CEPIT, buscando el nivel de confianza más cercano a la realidad, dando el mismo un valor del orden del 95\% con un margen de error del 15\%.

Con relación a las variables que fueron consideradas podemos mencionar: edad e identificación sexual, antigüedad total en el sector, capacitación, remuneración e incentivos al personal.

A partir de las consideraciones previas, el presente estudio se divide en tres grandes núcleos: en el transcurso del primero se realizara una explicación general sobre el capitalismo cognitivo y la nueva organización de las actividades en la empresa, puntualizando en la perspectiva sobre el suceso de rotación laboral. Luego, se lleva a cabo la caracterización de los trabajadores informáticos como protagonistas del capitalismo cognitivo, aquí se busca resaltar las especificidades de los trabajadores incluidos en las empresas del sector. Por último, se dará cuenta sobre los mitos y realidades de la rotación laboral analizando las variables ya descriptas y exponiendo los resultados de la encuesta.

\section{Capitalismo cognitivo y la nueva organización de las actividades en la empresa}

A diferencia del capitalismo industrial, en el cual el objetivo era maximizar la ganancia, en donde el trabajador debía adaptarse al ritmo de una labor específica y repetitiva con una organización de la producción piramidal, rígida también conocida como Fordismo. Y, cuya organización se sustentaba en una cronometrización en el tiempo de ejecución del trabajo o Taylorismo descripto por (Coriat, 1998) en el libro "El taller y el cronómetro". Hoy, asistimos a un tipo de capitalismo productor de servicios que requiere de otros dispositivos basados en: la profesionalización técnica, el trabajo grupal y participativo, es decir una organización del trabajo más horizontal y flexible. En esa línea:

Lo denominamos como "una fábrica difusa", en donde encontramos la organización del trabajo descentralizado, de un lado, y las diferentes formas de tercerización, por otro. Aquí se puede medir hasta qué punto el ciclo del trabajo inmaterial ocupa un papel estratégico en la organización global de la producción. (Lazzarato y Negri, 2001: 11) 
En esta nueva organización del trabajo, o capitalismo cognitivo, el factor clave de la productividad o principal fuente de la acumulación está determinado por el conocimiento. A este respecto, si el conocimiento está en todas partes, lo que cuenta es medir su intensidad, (Fumagalli, 2010) y su replicabilidad, (Rullani, 2000).

En ese mismo sentido, puede advertirse que en el desarrollo del capitalismo cognitivo un hecho indiscutible es que las tecnologías de la información y la comunicación han permitido una disminución de los costos y de los tiempos necesarios para la circulación de la información y del conocimiento codificado.

Ahora bien, las transformaciones conducen a un nuevo modelo de organización del trabajo cognitivo, que autores como (Vercellone, 2000: 67) denominan como "la nueva división social del trabajo". Esta tipología, tiene como característica saliente el proceso de rotación del personal, que sin duda origina costos indirectos y disminuye la posibilidad de obtener ventajas competitivas dinámicas.

Sin embargo, este tipo de organización induce a una doble desestabilización de los principios que regulaban la relación empresario-trabajador, y de los dispositivos de control que se ejercían respecto al trabajo durante el capitalismo industrial. Dado que por una parte está presente la incerteza estructural relacionada con la relación laboral que constituye una de las fuentes del problema.

Esto es, la empresa compra a partir del contrato la puesta a disposición por parte del trabajador de una cantidad de tiempo y del Know -How y el Know What (Lundvall, 2006) incorporado de los asalariados. En actividades como por ejemplo la producción de software, el trabajo no se cristaliza más en un producto separado del trabajador: el producto permanece incorporado en el cerebro del trabajador y en consecuencia es indisociable de su persona.

De otra parte, para los asalariados el trabajo no consiste en actuar sobre materia inanimada, sino sobre el hombre mismo en una relación de coproducción de servicios. De hecho, ni la actividad del trabajo, ni el producto, pueden ser realmente estandarizados, en definitiva la organización de la producción descansa sobre una cooperación autónoma del trabajo.

Esta cooperación autónoma del trabajo, por un conjunto de motivos, puede llegar a disminuir o bien a concluir. Cuando acontece podemos estar en presencia de la rotación laboral como suceso. La misma, puede definirse como el derecho a buscar nuevas oportunidades y nuevos alicientes económicos y 
profesionales para mejorar el status personal y profesional, es algo consustancial a la naturaleza humana y entraña múltiples aspectos positivos para el desarrollo de la carrera profesional del individuo (Rodríguez Fernandez, 1998).

La rotación laboral, como suceso económico-social preocupa a los gestores de las empresas en general y del rubro informático en particular por las pérdidas que ocasiona, en tiempo de trabajo y recursos, siendo mencionada con más frecuencia cuando se los consulta. Por ejemplo, en la entrevista realizada a un informante clave el mismo expresa que:

A nivel empresa, la movilidad si bien en algún nivel es sana, la empresa siempre pierde, porque lo que venden las empresas es conocimiento sobre una tecnología, entonces el conocimiento es muy importante porque para capacitar a quien lo realiza se necesita un año, perder un recurso es perder mucho dinero; por tanto siempre se intenta tener la menor rotación posible. Las empresas que tienen venta de equipos o venta de horas hombre quizás tienen menos impacto, pero toda empresa tiene impacto. Porque uno tiene un proyecto montado y si se va una persona clave del equipo no hay como reemplazarlo. (JP, Director de Q4Tech)

Esta percepción es avalada por los informes periódicos sobre el sector elaborados por el Observatorio Permanente de Software y Servicios Informáticos (OPSSI), que muestran que además de los costos salariales y la escasez de personal calificado, la rotación aparece como uno de los problemas más apremiantes.

En el siguiente grafico realizado por el observatorio OPSSI se expone la evolución de la rotación laboral de las industrias del sector en Argentina. 
Figura 1. Evolución de la rotación de personal

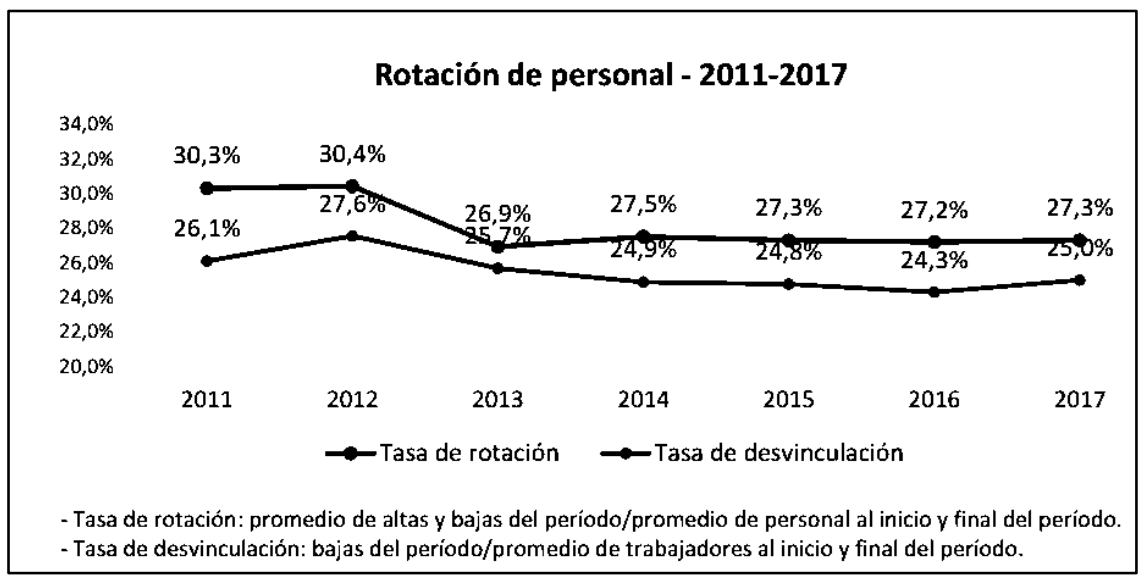

Fuente: Reporte anual del Sector Software y Servicios Informáticos de la

República Argentina (OPPSI, 2017)

En la figura, puede observarse que la rotación se ha mantenido estable en promedio durante los últimos cinco años de la serie estudiada. Aun así, sigue siendo alta si se tiene en cuenta que mayoritariamente pertenecen a empresas del ámbito de la Ciudad Autónoma de Buenos Aires, y si se las compara con las existentes en provincias, como Buenos Aires, Córdoba o Rosario. O bien, si se realiza un paralelo respecto a la tasa anual acumulada de rotación del empleo privado en general en las mismas ciudades. En este último caso, está en el orden del $2 \%$ a nivel nacional. En tanto, en córdoba es del orden del 2.1\% promedio mensual, mientras que en Rosario es del orden del 1,8\%, Capital y gran buenos aires del 1,9\%. 


\section{Figura 2. Promedio de rotación anual comparado con otras localidades}

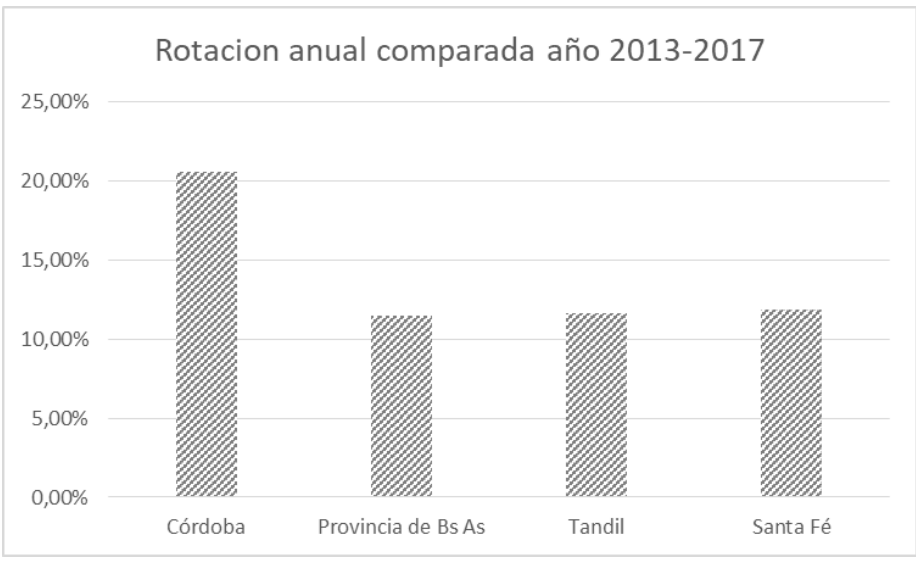

Fuente: elaboración propia sobre la base de datos generados por la encuesta realizada por el proyecto

Específicamente, en Tandil los empleados de las empresas que forman parte de la cámara tienen un nivel de rotación del $11.6 \%$ anual promedio, según datos que arrojó la encuesta. Cuyo espacio temporal, se sitúa en el transcurso de los años 2013-2017. Es decir, esta problemática se constituye en forma menor respecto a la media informada para el ámbito nacional que pudo observarse en el grafico anterior proveniente de las cifras de la OPSSI.

Aun así, se realizó una comparación respecto a la totalidad de la Provincia de Buenos Aires, a partir de encuestas realizadas por Sysarmy, que arrojo una cifra equivalente $11,5 \%$; y una comparación respecto a otras provincias en las cuales se encuentran los Polos Tecnológicos que fueron creados en el mismo periodo que el Polo Tecnológico Tandil, como Santa Fe y Córdoba. En esa línea, se observa que Tandil tiene una tendencia similar a la que podemos encontrar en Santa Fe 11,9\%, mientras que la rotación laboral se torna mucho menor respecto a Córdoba que asciende al 20,6\%.

Por otra parte, también se podría sugerir que el proceso de rotación se vincula necesariamente con la extensión del mercado laboral, dado que por ejemplo el tamaño del mercado laboral en Córdoba 5100 puestos (Borrastero y Motta, 2011), en Tandil según cifras de CEPIT existen aproximadamente 2000.

Al respecto, en el marco de la CEPIT, y ya como parte del estudio de la rotación laboral como suceso nos indagamos acerca de la cantidad de veces que dicho personal rotó en el transcurso de los últimos cinco años: 
Figura 3. Rotación Laboral en empresas informáticas asociadas a CEPIT

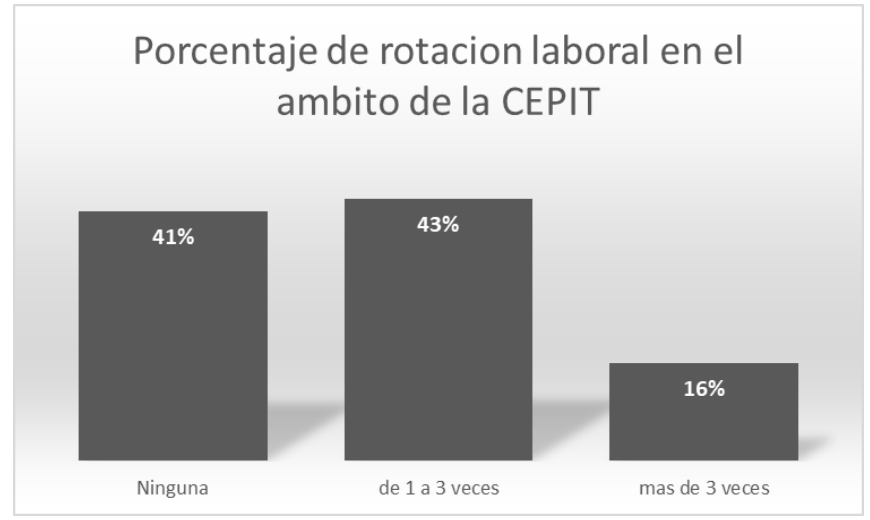

Fuente: elaboración propia sobre la base de datos generados por la encuesta realizada por el proyecto

Según los datos obtenidos, la misma estuvo en el orden de 1 a 3 veces. Ello implica que un trabajador rota en promedio cada año y medio aproximadamente. En tanto en un examen puntual podemos expresar que del total de los trabajadores, un 58\% tiende a realizar rotación entre diferentes empresas comprendidas en este sector en diversos estadios dentro de su trayectoria profesional.

Ahora bien, si nuestra visión se enfoca a la rotación laboral como proceso, podemos observar que la misma es producto de un complejo entrelazamiento de variables individuales que conducen a una toma de decisión por parte del empleado de abandonar su puesto de trabajo.

$\mathrm{Y}$, que a partir de la generación de diversos mecanismos o incentivos puede disminuir dicho proceso. Al respecto, Dessler y Varela Juarez (1996) definen a los incentivos como: aquellos planes que relacionan la remuneración con el desempeño en el trabajo. Expresando también, que los incentivos son una herramienta útil para crear y mejorar la motivación del empleado, ya que a través de estos planes se busca influir en su comportamiento, motivándolos también en los diferentes aspectos que están relacionados con el cumplimiento de su trabajo y su desempeño dentro de la empresa.

En la práctica, conforme a lo revelado por los entrevistados, varias empresas del sector generan programas orientados a la retención de sus colaboradores diseñando lugares de trabajo amigables, o a través del pago de diversas prestaciones, beneficios y servicios. 
O bien, se ponen en juego estrategias como la visibilización de un horizonte amplio en la empresa, y planes de carrera. Lo cierto, es que las diferentes soluciones se definen a lo largo del tiempo y dependen de los procesos de aprendizaje y experimentación llevados a cabo por las empresas, y de un equilibrio entre el contexto operacional y el institucional.

\section{Trabajadores informáticos como protagonistas del capitalismo cognitivo}

La configuración del capitalismo cognitivo, está acompañada de transformaciones en los rasgos de los trabajadores en general, y sobre todo en aquellos tecno-informacionales. Por ello, la finalidad está centrada en profundizar sobre las características de quienes hoy se desempeñan en el sector. A tal fin, se realiza una descripción de esta población en general, y especialmente aquellos que pertenecen a empresas de servicios informáticos que están incluidas en la CEPIT.

En líneas generales, puede advertirse que los integrantes del sector tienen connotaciones totalmente diferentes y específicas con respecto a los trabajadores que participaban en el capitalismo industrial, o sobre otros trabajadores que trabajan en el sector de servicios.

Por ejemplo, en la composición de ese núcleo de trabajadores en base a la identificación por género:

Figura 4. Porcentaje de trabajadores de la CEPIT por identificación de género.

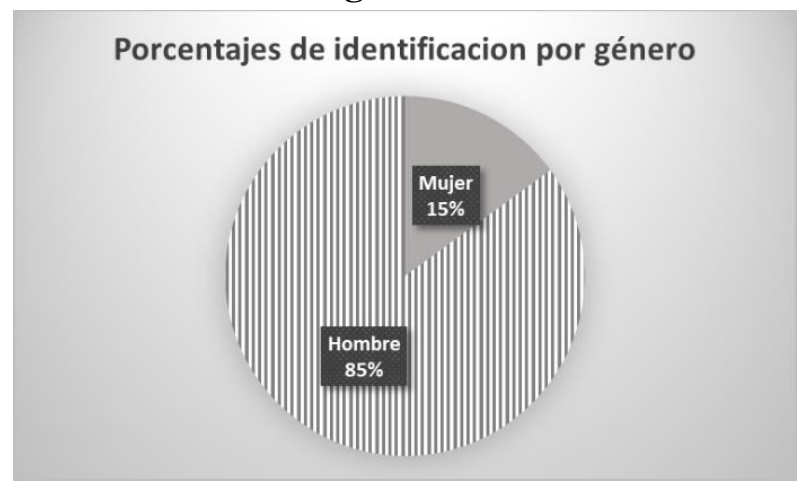

Fuente: elaboración propia sobre la base de datos generados por la encuesta realizada por el proyecto 
En la actualidad, la informática es un sector donde predominan los hombres, y la brecha existente comienza desde la formación técnica. Específicamente, puede señalarse que a escala nacional las carreras de educación superior seleccionadas por las mujeres relacionadas con la informática ocupan el anteúltimo lugar, y son elegidas sólo por un 2,3\% según el informe 2013 patrocinado por la Fundación Sadosky cuyos autores son Zukerfeld, Botta, Dughera, y Yansen. El mismo informe, amplia los datos y expresa que en el caso de los hombres computación e informática aparecen como las carreras con más potencial favoritismo, con un 19,4\% (Zukerfeld et al, 2013).

En términos locales, dicha características se reproduce, si por ejemplo se toman la cantidad de egresados de la Facultad de Ciencias Exactas.

Figura 5. Egresados por género periodo 2010-2015

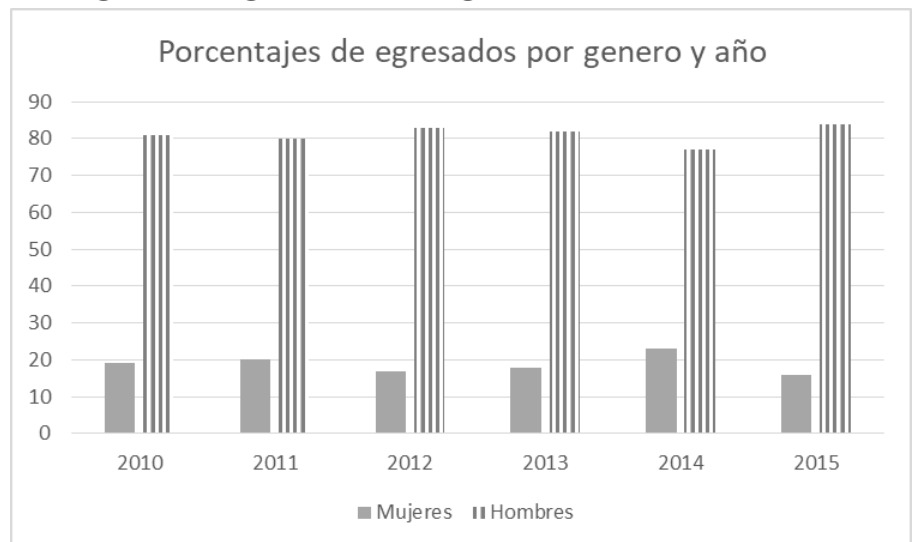

Fuente: elaboración propia en base a cifras del Anuario de Estadísticas de la Secretaria de Políticas Universitarias.

En esta variable, la brecha se encuentra en el orden del $60 \%$ entre uno y otro género. Esta realidad no solo deriva de las elecciones, pues aquí también entran en juego cuestiones como las representaciones sociales sexo-genéricas que determinan el tipo de participación en distintas carreras terciarias y universitarias, en donde las carreras de informática son aquellas percibidas como menos adecuadas para las mujeres entre las existentes.

También, entre otros aspectos, encontramos la internalización de ciertas pautas respecto de la relación tecnología-género. Al respecto, puede señalarse que algunas habilidades asociadas a las que se utilizan en los procesos 
productivos de software tienden a estar más afianzadas en el género masculino según consta en el informe mencionado.

Una segunda particularidad está vinculada a las edades de la población. Del análisis de la encuesta surge que la muestra está compuesta mayoritariamente por trabajadores con un rango de edades entre 25 y 40 años, tal y como puede apreciarse en el grafico que se presenta a continuación:

Figura 6. Distribución de población laboral de la CEPIT por edades.

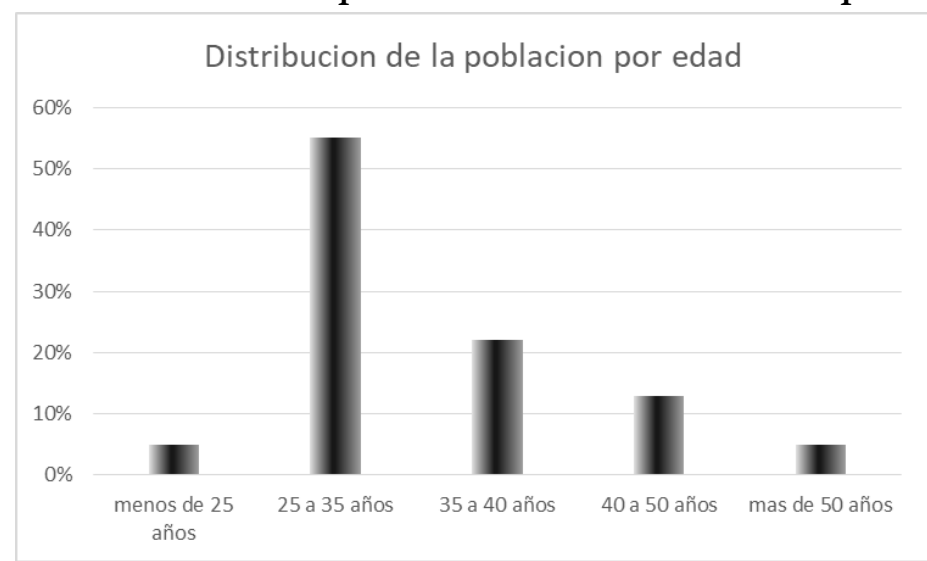

Fuente: elaboración propia sobre la base de datos generados por la encuesta realizada por el proyecto

Aquí, una posible explicación sobre el tema es que para este sector la edad de los postulantes comprendida en ese perfil etario es un factor relevante al momento de decidir la contratación. La situación responde a una preferencia de las empresas por un rango de empleados más jóvenes, que puedan formar según sus necesidades particulares y que cuenten ya, en muchos casos, con habilidades para el trabajo.

Sin embargo, esta tendencia deja en evidencia un problema profundo: la reducción del período de empleabilidad, dado que las edades más identificadas tanto con el comienzo como con la finalización de una trayectoria laboral disminuyen profundamente en cantidad de trabajadores.

Es decir, a las restricciones de empleados tecnológicamente capacitados se agregan estas limitaciones de acceso al trabajo para los perfiles más adultos, y las dificultades derivadas del tiempo de adquisición de habilidades en la carrera que experimentan los candidatos más jóvenes para insertarse por primera vez 
en el mercado laboral, determinando un rango cada vez más ajustado de edad para ser elegible para un puesto en las empresas informáticas.

Otra especificidad, está referida a que las estructuras profesionales para realizar su inserción en el mercado laboral perteneciente al sector informático y ejecutar su labor diaria requieren de la adquisición del factor clave, es decir, la adquisición de conocimiento tecnológico especifico que se logra a partir de la capacitación en instituciones de Educación Superior donde predominan las carreras universitarias.

Figura 7. Distribución de los trabajadores de CEPIT por nivel de estudio formal alcanzado

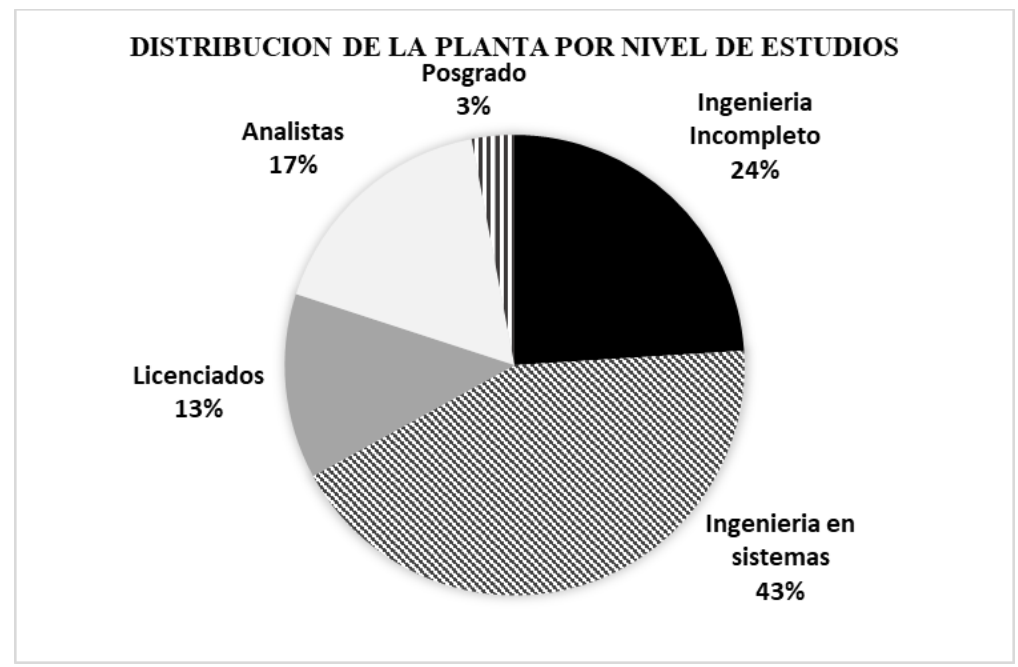

Fuente: elaboración propia sobre la base de datos generados por la encuesta realizada por el proyecto

A simple vista, puede indicarse que es un sector donde el nivel de estudios formales del personal es elevado, siendo el $43 \%$ de los trabajadores ingenieros en sistemas; y un 17\% son analistas, mientras solo el 3\% posee título de post grado y un $24 \%$ han sido captados antes de la finalización de sus estudios universitarios.

En este punto, cabe señalarse que la formación de base se considera elemental para el ingreso a la vida laboral, y la creación de nuevas aptitudes es un factor importante a toda escala, aun así la carrera de ingeniería de sistemas de la UNICEN tiene un promedio de duración de 10,6 años real, más allá que en teoría este estipulada en cinco años. Dicha cuestión afecta la trayectoria 
formativa, conduciendo a que el tiempo de aprendizaje se superpone con el tiempo de trabajo. Tal como lo describe un informante clave:

La gran mayoría de los trabajadores del sector en Tandil han sido formados en la universidad pública, nosotros creemos que sin la universidad como formadora de esa mano de obra no podría existir una masa laboral de aproximadamente 2000 personas. En este momento, es hasta más grande que la masa característica de Tandil que fue la industria metalmecánica. El tema, es que antes que se terminen los estudios ya existe inserción laboral, sobre todo en el sector privado, cuando uno estudia carreras relacionadas a la informática sabe que va a tener trabajo el día de mañana, pero por otro lado, las empresas van a tomar esos recursos que son escasos antes de que se termine con la carrera. Eso lo que lleva a que mucha gente haya invertido dos, tres, o más años de su vida estudiando, no se llega a recibir empieza a trabajar y termina dejando los estudios porque el trabajo comienza a demandar tiempo y ese tiempo se le resta al estudio. (JR, AGC Tandil)

Por tanto, las empresas tienden a la captación de los alumnos que ya han superado la formación básica. Y si bien, para los alumnos constituye una forma de ingresar al ámbito laboral y complementar su formación. Es decir, acceden a conocimientos prácticos, obtienen experiencia, y se familiarizan con el ambiente de trabajo y la ocupación misma contribuyendo a que adquieran disciplina y responsabilidad necesaria que exige el desempeño en el trabajo; genera como consecuencia no deseada una modificación en los índices de graduación de la carrera de Ingeniería en Sistemas.

Un punto clave en este aspecto, se vincula con los compromisos hacia la empresa, y los requerimientos de la jornada laboral. Dichas variables en el tiempo pueden constituirse como causa de deserción de la carrera, generando un círculo vicioso pues las empresas contratan a los alumnos de los primeros años, con una formación incompleta agravándose aún más si no se realiza una capacitación constante, pero luego se exigen competencias de base para continuar en los proyectos.

Por lo expuesto, el conocimiento técnico es condición sine qua non aunque no se solicita certificaciones. En verdad, el título no es una exigencia hoy para este mercado debido a que la demanda supera la oferta, si lo son en general las capacitaciones para adquirir habilidades específicas, y aprendizaje de competencias diferenciadas, dada la obsolescencia permanente de los productos a causa de los nuevos avances tecnológicos. Respecto a este tema: 
Sorpresivamente, el sector SSI muestra los rendimientos salariales más bajos del conjunto de sectores laborales del país para cada escalón de logro educativo, particularmente en lo que refiere a los títulos de grado y estudios de posgrado (Rabosto, 2018). Mientras que, para el conjunto de los sectores laborales (agregado), tener un título universitario incrementa en promedio un $50 \%$ el salario horario, en el sector de SSI lo hace solo en un 18\%. Por otra parte, mientras que en el agregado poseer estudios de posgrado incrementa en promedio un $12 \%$ el salario horario frente a quienes tienen estudios universitarios completos, en el sector de software lo hace sólo un 1\%. Asimismo, la estimación del rendimiento salarial aportado por cada año de escolaridad formal indica que el mismo es en promedio de 6,3\% para el sector de software frente a un $9,6 \%$ en el conjunto de los sectores laborales. (Rabosto y Zukerfeld, 2019: 26).

En sí, un perfil satisfactorio para la empresas está dado por personas con conocimientos técnicos de base y adaptación a las innovaciones del mercado, sumado a la acreditación de su continua capacitación para mantenerse a la par de los requerimientos del sistema. Pues, las nuevas exigencias laborales por parte del sistema productivo basadas en conocimientos hacen que las habilidades contenidas en los individuos deban transformarse y reincorporarse en forma permanente, es decir, conllevan implícita la necesidad de ampliar el conocimiento, que (Lundvall, 2006) denomina Know -How (saber cómo) y el Know What (saber qué).

En tanto, la última variable de estudio seleccionada para caracterizar la población ha sido la antigüedad en el sector. 


\section{Figura 8. Distribución de la población por antigüedad en empresas pertenecientes a la CEPIT}

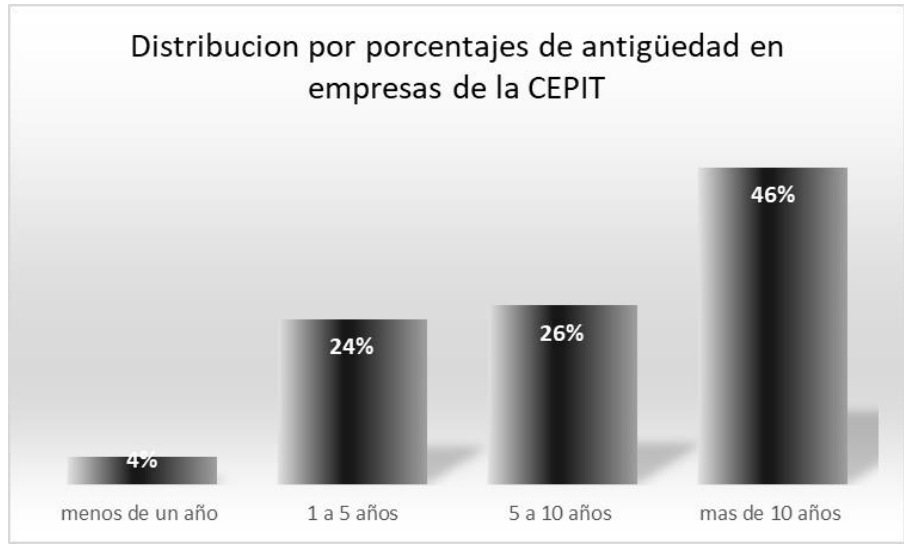

Fuente: elaboración propia sobre la base de datos generados por la encuesta realizada por el proyecto

Tal y como se describe en el grafico la composición de la población de estudio en su mayoría tiene como experiencia en el sector entre 1 a 10 años en un $50 \%$, y casi la misma cifra alcanzan aquellos que tienen una experiencia de más de 10 años estableciéndose en el orden del 46\%.

En síntesis, si bien se puede dar cuenta acerca de las tendencias encontradas respecto a la especificidad de los trabajadores del sector, se requiere de una profundización respecto de su actuación en el mercado para determinar los motivos que inducen al proceso de rotación laboral. Por ello, en el próximo apartado se realizará una correlación de las distintas variables analizadas, cuya información deriva de las encuestas efectuadas en el transcurso del estudio.

\section{Mitos y realidades sobre la rotación laboral}

En el transcurso de la introducción se planteaba la idea que la rotación laboral es el suceso visible, sin embargo, tras de ella subyacen otros hechos vinculados, por ello en esta sección se dará cuenta acerca del conjunto de ideas preconcebidas que pueden señalarse como causas de la rotación. En esa línea, nos interpelamos acerca de si puede realmente considerarse que exista una motivación principal, y en todo caso, cual es la que prevalece. 
Figura 9. Porcentaje de rotación laboral medidos por variables de estudio

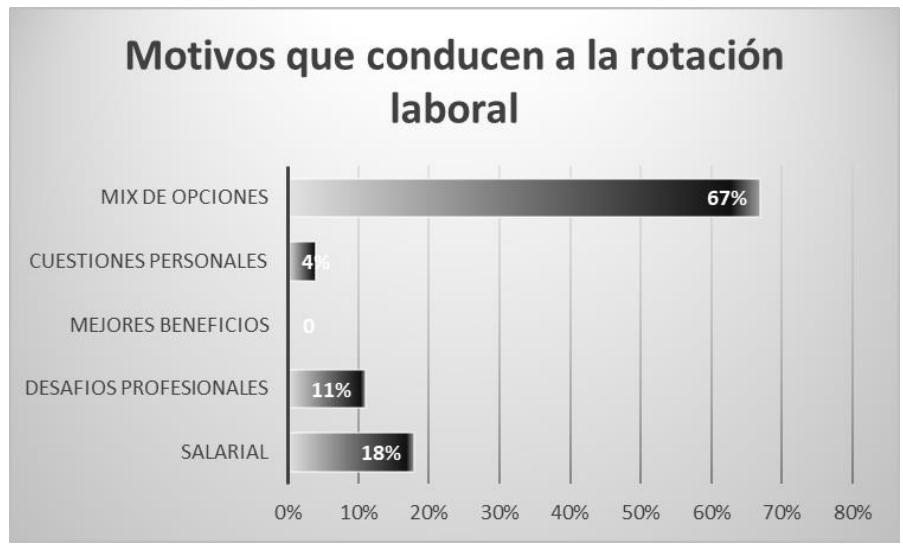

Fuente: elaboración propia sobre la base de datos generados por la encuesta realizada por el proyecto

Del análisis de la encuesta, surge claramente que se constituye en proceso, porque la misma representa un conjunto de hechos a las cuales se debe atender, es decir, está enlazado con diversas variables de funcionamiento dinámico que en conjunción estructuran la complejidad de la situación.

Por otra parte, si bien es cierto que la cuestión salarial ha sido seleccionada como un factor de impacto, puesto que se encuentra segunda en el ranking, del mismo modo que aquellas cuestiones vinculadas con cuestiones subjetivas su tendencia va muy por debajo de mix de opciones.

\subsection{El salario neto y beneficios como un motivo de la rotación laboral}

Más allá del conjunto de condiciones que producen la rotación laboral, debe considerarse que los trabajadores han seleccionado como uno de los motivos más importantes de la rotación laboral la cuestión vinculada al salario. Particularizando en esta variable, para el 18\% es única opción, sin embargo, la misma se encuentra contemplada como segunda en las elecciones generales.

Aun así, un análisis de la evolución de los mismos, muestra que en la postconvertibilidad ha tenido uno de los incrementos más bajos de toda la economía y, esta situación empeora si el ajuste se realiza por inflación, tal como lo describen (Rabosto y Zukerfeld, 2019) es el único sector donde el poder 
adquisitivo del salario promedio ha caído entre 1998 y 2015. Según sus estimaciones la caída fue del 20\% (Rabosto y Zukerfeld, 2019).

Desde la visión de la empresa, el establecimiento de un monto salarial por empleado es una cuestión que se relaciona con diferentes variables macroeconómicas, tal y como lo expone uno de los entrevistados:

Argentina es un país complejo en lo que se refiere a salario, porque tuvo muchos años de inflación no declarada por lo cual no se sabe si se estuvo bien con salarios respecto a la inflación, existen años en los cuales se planifica en base a un porcentaje de inflación y termina en más del doble, con lo cual están todas las empresas re-planificando para que los empleados no pierdan poder adquisitivo, la plata que se tenía se usa para soportar la inflación y no para hacer evolucionar el salario de la gente. Todo eso va en decrecimiento de los salarios de sistema. Hoy un salario inicial de sistemas está casi como un salario de empleado de comercio. Pero tenemos los beneficios en compensación. (JP, Director de Q4Tech)

Más allá de la visión empresaria, una primera hipótesis puede ser que las modalidades de contratación en las cuales la flexibilidad, la individualidad se presenta como características conducen también a una modificación en la apreciación del salario como tal.

Por lo descripto, encontramos como rasgo general en los trabajadores una superación de la tradicional de la imagen del trabajador asalariado dependiente y con contrato indefinido, que es sustituida por trabajo independiente con formas laborales cada vez más flexibles. Este fenómeno, puede ser observado tanto en la fragmentación del trabajo como en el cambio cualitativo de la propia prestación laboral asalariada que prescinde de las formas contractuales que esta solía asumir (Fumagalli, 2010).

Por otra parte, esa figura de trabajador autónomo con contratación laboral flexible hace que se produzca un crecimiento del 10,7\% en el empleo del sector SSI entre 2010 y 2017; y que sea este el principal indicador de crecimiento sostenido del sector. Sobre todo, al contrastarlo con la generación de empleo privado por parte de la economía argentina en general. Sin embargo, no deja de ser un hecho, que la flexibilidad de contratación brinda espacio a una falta de identificación clara de los trabajadores con una empresa, y a la búsqueda de reconocimiento a partir del salario.

De este modo, se trata de un cambio notable en la medida en que ya no se habla de remuneración del trabajo en y por sí mismo, independientemente del 
producto o del servicio en cuestión, sino de pago por las capacidades demostrables a partir de la experiencia. En el caso de Tandil, según relata un entrevistado:

En el salario es producto de la experiencia en el sector, o en alguna tecnología especial que se está buscando. Esto es lo que más pesa. Y también el poder de negociación. La negociación es el número definitivo del sueldo, y ayuda si no se consigue el perfil que se está buscando. Y una vez que se está incluido en una empresa para que el sueldo crezca hay una evaluación individual de cada empleado, y según el rendimiento, se puede percibir un aumento que muchas veces se refleja en un nuevo cargo como pasar de junior a senior, o arquitecto o líder, porque cada empresa maneja sus títulos de posición. No hay un presupuesto atado al proyecto y si el proyecto va bien no se otorga un extra. El sueldo va en función del rendimiento y la experiencia. (JR, AGC Tandil)

La pregunta en este caso es ¿Qué mecanismos utilizan las empresas para retener el personal?

Ante rotación laboral como suceso, y en la búsqueda de la retención de personal, las empresas han puesto en práctica diferentes mecanismos o estrategias entre las que se cuentan pagos no remunerativos al interior de la estructura salarial que se traducen en: beneficios otorgados más allá de la percepción salarial, así como también sistemas de capacitación, y tiempo de cumplimiento de la tarea fuera de la empresa, e incentivos de carrera en las trayectorias individuales, entre otros.

Una primera cuestión, entonces es observar las variables que se tienen en cuenta a la hora de estipular el monto salarial total más allá de la percepción en forma de dinero. En esa línea, puede señalarse que el salario como forma de la retribución, es compensado por el pago de adicionales en concepto de prestaciones remunerativas no bonificables con forma de beneficios con un monto máximo por empleado.

En el caso de las empresas de la CEPIT, del total de los encuestados un $63 \%$ recibe beneficios, que pueden ser de una categoría o bien de varias a la par. La forma que asumen los mismos puede observarse en el siguiente gráfico: 


\section{Figura 10. Beneficios ofrecidos por las empresas destinados a la retención}

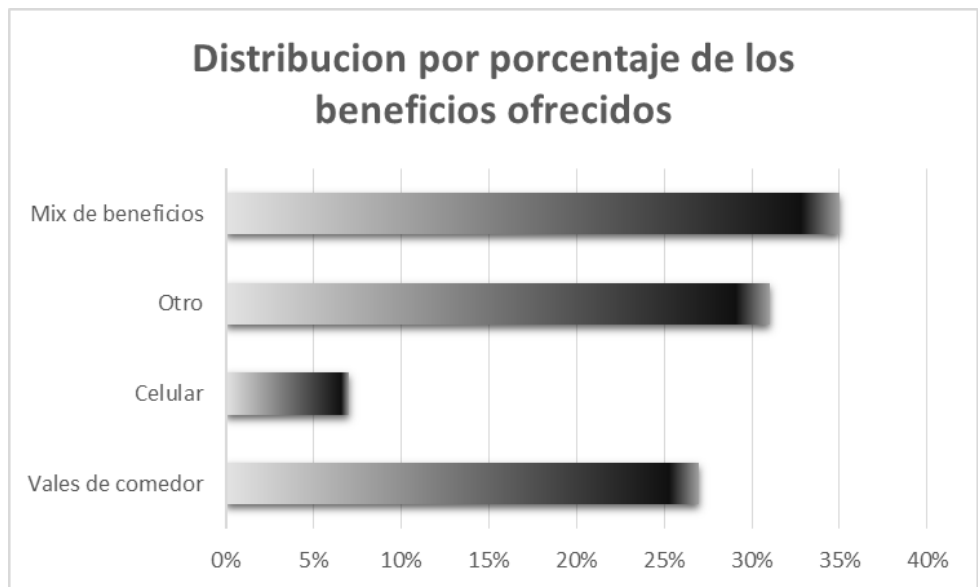

Fuente: elaboración propia sobre la base de datos generados por la encuesta realizada por el proyecto

Entre las opciones más seleccionadas encontramos que en realidad las empresas en su mayoría ofrecen un mix de beneficios $27 \%$ entre los cuales pueden contarse: obras sociales con amplias prestaciones, descuentos en instituciones educativas, entre otras; que en algunos casos cubren prestaciones que serían adquiridas pero cuyas erogaciones provendrían del salario. Tal como lo expresa el informante clave:

Hoy todas las empresas dan beneficios, como medicina pre-paga para grupo familiar, días libres, se hace un acompañamiento a quienes están estudiando; es decir, hay toda una cobertura que se da por fuera de lo que es salario. Que es importante para una PyME, pues en una corporación grande es natural; ahora una PyME en general no cubre esos beneficios y las empresas de sistemas si las están cubriendo.

Nosotros entre las empresas peleamos por los talentos, con lo cual nosotros pretendemos darle prestaciones que sean un diferencial, porque para el futuro empleado también puede ser una forma de definir con cual empresa se queda. (JP, Director de Q4Tech) 
Aquí, la interpelación va en función de si pueden en algún punto subsanar estos beneficios las diferencias entre salario real y salario neto percibido por el trabajador.

Figura 11. Correlación entre rotación salarial y percepción de beneficios.

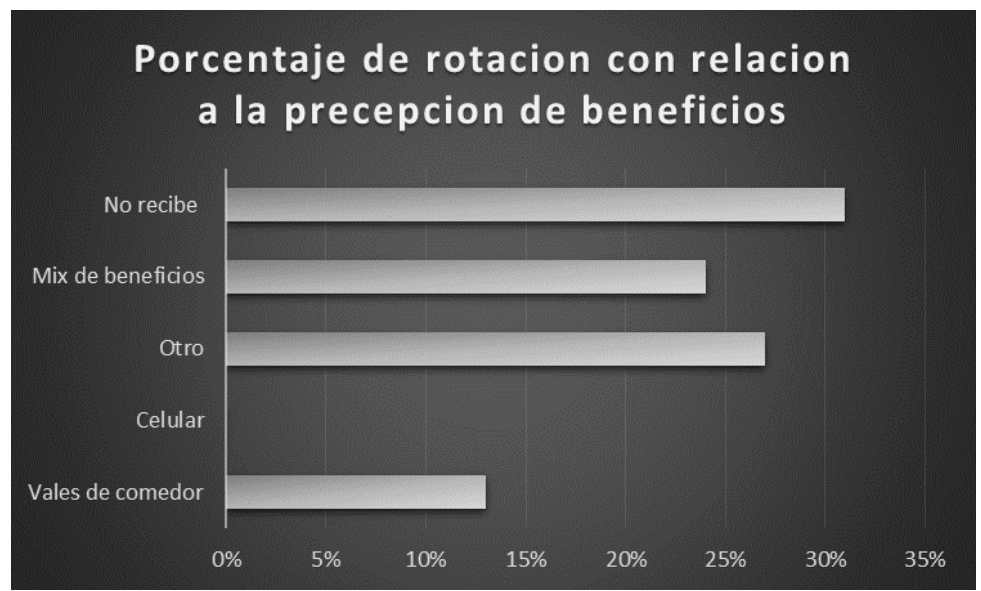

Fuente: elaboración propia sobre la base de datos generados por la encuesta realizada por el proyecto

Tras la observación del gráfico, concluimos que el mayor porcentaje de rotación se encuentra en aquellos que no perciben beneficios cuya cifra se establece en el orden del $31 \%$. Es decir del total de agentes que no percibe beneficios un $91 \%$ de ellos busca otra empresa. Por tanto, se constituye en una estrategia válida hasta cierto punto. Pues, si bien la rotación se produce de todos modos la percepción de beneficios disminuye el número de personas que la llevarían a cabo.

Más allá de las consideraciones, puede señalarse que este trabajador autónomo para tener el poder contractual suficiente para imponer el pago de la propia prestación de forma favorable a su persona, debe mantener su competitividad en el mercado de trabajo. Por tanto, su plusvalor no se encuentra solo en el nivel absoluto de su saber y del alcance de su conocimiento, sino su especialización exclusiva. 


\subsection{Diferencia entre tiempo de trabajo y tiempo de ocio}

Las personas dedicadas al campo de la informática sintetizan la figura del asalariado y la del empresario. Puntualmente, en estos casos confluyen el hecho que su remuneración es estrictamente dependiente de la autoexplotación de su propia capacidad de trabajo, así como del poder contractual que ocupa en la estructura jerárquica del mercado dentro de una cadena productiva cada vez más compleja y diferenciada.

Se puede entonces avanzar en la siguiente tesis: el ciclo del trabajo inmaterial es preconstituido por una fuerza de trabajo social y autónoma, capaz de organizar el propio trabajo y las propias relaciones con la empresa. Ninguna organización científica del trabajo puede predeterminar esta capacidad y la capacidad productiva social. (Lazzarato y Negri, 2001: 12)

Desde este punto de vista, es el trabajador quien intenta definir en muchas ocasiones el propio espacio físico de trabajo, pero esto a su vez depende algunas veces de la flexibilidad contractual y en otras de los acuerdos otorgados por la empresa respecto a la organización de su tiempo laboral. Esta domesticación del trabajo autónomo (Fumagalli, 2010), es variable asimismo respecto a la categoría que se ocupe dentro de la empresa. Tal como se relata en una de las entrevistas:

Trabajar desde la casa es una flexibilidad que en Tandil se puede dar por el tiempo de traslado, en Buenos Aires no es tan flexible, aun así muchas ofertas laborales proponen un día de home-office, o dos pero es todo el día, no a tiempo parcial, acá se puede dar esa flexibilidad dependiendo de la necesidad. El problema está en los Juniors, que requieren de una guía porque pueden surgir dudas por falta de experiencia, y al no estar en el mismo lugar físico que sus compañeros se pueden generar contratiempos, o que se rinda del mismo modo que cuando estas en la oficina, por eso es más difícil dar esos beneficios a un junior. JR, AGC Tandil)

En ese sentido, la domesticación va estrictamente ligada a una percepción diferente del tiempo de trabajo. Para (Baumann, 2003) el tiempo/espacio significaba horario, lugar de trabajo y salario. El tiempo/espacio era una unidad 'rutinizada', localizada, productiva en la fábrica que otorgaba seguridad, concreción, visibilidad, asociación. En las dinámicas de globalización el 
tiempo/espacio se torna invisible, sin medida de horario para la constatación del trabajo, porque la relación capital trabajo es extraterritorial, individualizada, invisible e insegura.

En esta nueva forma de organización del trabajo, el tiempo no es medible según los criterios tradicionales que favorecen un alargamiento de la jornada de trabajo, o bien, que miden el tiempo efectivo de trabajo. En ese sentido, puede pensarse en que "La consecuencia es que el tiempo de trabajo y el tiempo de vida se superponen, con neto predominio del primero sobre el segundo" (Fumagalli, 2010: 205).

Ahora bien, el tiempo de trabajo en el hogar constituye una variable para analizar dentro de las negociaciones contractuales. Según la encuesta realizada de aquellos trabajadores que realizan parte de su trabajo en forma domiciliaria, se encuentran en el orden del 46\%, y una antigüedad mayor a 10 años.

\section{Figura 12. Correspondencia entre rotación laboral y trabajo en el hogar.}

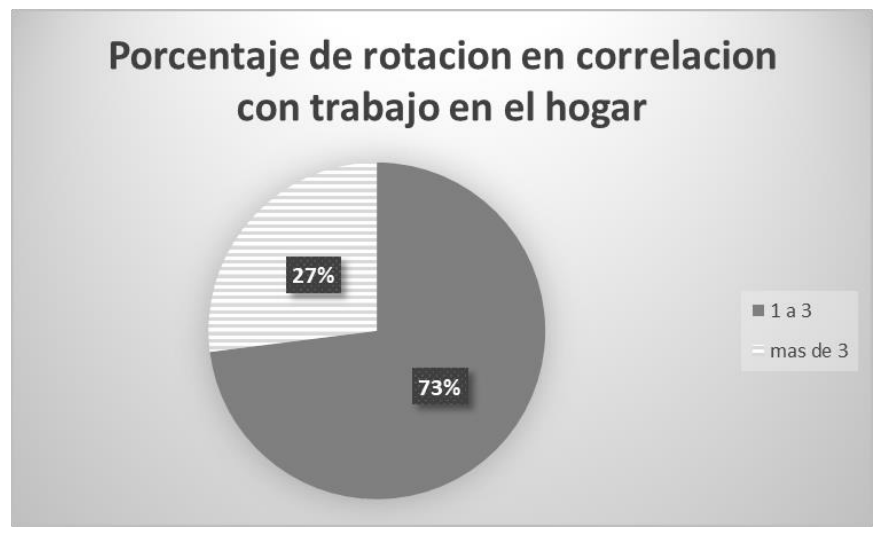

Fuente: elaboración propia sobre la base de datos generados por la encuesta realizada por el proyecto

El porcentaje expresado anteriormente, implica que buscar disminuir la rotación mediante la flexibilidad horaria y la domesticación laboral no necesariamente conlleva al efecto deseado. En el grafico precedente, puede observarse la asiduidad con que la mayoría rota. Claramente, la cifra predominantes es entre una y tres veces es decir se encuentra en el cuartil de mayor rotación dentro de la muestra de datos. Por lo cual, la posibilidad de 
realizar parte de su trabajo en forma domiciliaria no puede ser considerado como un beneficio que disminuya la rotación laboral.

Dicha cuestión, constituye una facilidad respecto a la organización de los tiempos del empleado en general, es decir, esta nueva característica de trabajador autónomo desarrolla un sentido de mayor propiedad de las reglas vigentes en el diseño de los espacios de trabajo, y al mismo tiempo, de menor aceptación de las reglas de otros.

Aun así, este tipo de organización cercena los ciclos socio-afectivos, el ciclo de la vida privada y el ciclo de la vida laboral, reduciendo la existencia a un único ciclo: vida laboral -vida privada.

La supresión de la separación entre vivienda y trabajo implica efectos evidentes sobre la productividad del trabajo, ya sea porque la movilidad vivienda-trabajo es un coste social y puede suponer gastos para la empresa, o porque esta supresión favorece un alargamiento de la jornada de trabajo y del tiempo efectivo de trabajo (Fumagalli, 2010: 206).

En realidad, las nuevas tecnologías permiten otras reglas no codificadas que de alguna forma no limitan el horario de trabajo de los empleados, tal y como ocurría en cambio con el trabajo asalariado debido a la existencia de acuerdos contractuales sobre el tiempo de trabajo; por tanto, así el tiempo de trabajo no es equivalente al tradicional tiempo de trabajo.

\subsection{Capacitación y rotación laboral}

La posesión de determinadas competencias, tanto personales como técnicas conforma el principal activo de estos trabajadores constituyéndose clave en la negociación contractual, como también en la determinación tanto de la rotación como de la desvinculación con las empresas.

Particularmente, los niveles de capacitación laboral en Tandil siguen los parámetros generales a escala nacional e informada por la OPSSI según se presenta en el grafico a continuación. 


\section{Figura 13. Porcentajes de personal capacitado en empresas que forman parte de la CEPIT}

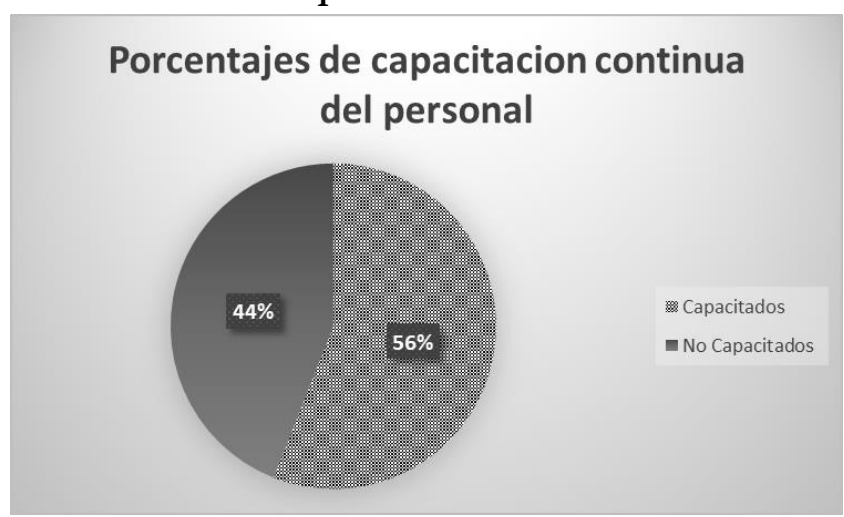

Fuente: elaboración propia sobre la base de datos generados por la encuesta realizada por el proyecto

El grafico expone que si bien existe un grado de capacitación alto probablemente el esfuerzo tendría que superarse, dado que la orientación general es hacia la adquisición permanente de nuevas capacidades técnicoprofesionales por parte de los individuos que participan de los procesos de producción, debido a que el conocimiento incorporado sirve como soporte de la innovación, y que es la base del progreso técnico aplicado a productos y procesos.

En esa línea, puede señalarse que existen diferentes perfiles de trabajadores informáticos en función de las herramientas que dominan y la complejidad de las actividades que realizan. Además, las exigencias del mercado laboral no solo se producen con respecto a un nivel de educación especializada; actualmente existe una relación entre las competencias personales, una actitud diferente respecto al trabajo y un cuestionamiento permanente que les permite ser innovativos.

Eso significa, sin lugar a dudas, un cambio radical de actitud, implica la búsqueda de una perspectiva que especifica el estudio de problemas relevantes; involucra una renovación del paradigma como denominaría (Kuhn, 1971) un modelo, un patrón de búsqueda o cuestionamientos. En ese sentido, tal como lo expone uno de los entrevistados:

Generalmente en las empresas, uno se hace carrera por sí solo, es tan grande el rubro y hay tantas tecnologías y roles que uno puede cumplir 
adentro de proyecto o dentro de una empresa que continuamente se aprenden nuevas tecnologías, uno llega hasta donde realmente quiere o puede. Probablemente porque si a uno le gusta, va a esforzarse por desarrollar la carrera en una empresa o va a ir cambiando de empresa para crecer y llegar a la posición deseada; pero para eso se requiere una capacitación continua. (JR, AGC Tandil)

Es decir, el trabajador requiere de capacitación continua para mejorar su desempeño en proyectos y tareas asignadas. El trabajo por proyectos, es un mecanismo utilizado en estos sectores dinámicos cuya experticia se vincula con el ámbito de las nuevas tecnologías de la información y la comunicación.

El trabajo por proyectos, si bien se realiza en equipo, cada individuo es responsable de su tarea y del cumplimiento de objetivos a través de acciones que requieren autonomía y capacidad de resolución, y se asocian al conocimiento y manipulación del tema en cuestión. No obstante, la experiencia demuestra que bajo lo que se denomina trabajo en equipo se encuentra una heterogeneidad muy grande de situaciones, porque los estudios han demostrado distancias importantes entre el discurso simbólico y la realidad de la empresa (Novick, 2008).

Este perfil requerido por las empresas del sector informático, con capacidad técnica especializada y conceptual, no es abundante en nuestra sociedad. Las capacidades necesarias para convertir ideas en acción, desplegar conocimientos en el trabajo, trabajar en equipo, comunicarse y seguir aprendiendo toda la vida, son parámetros que la empresa debe promover a partir de la capacitación.

\subsection{Experiencia en el sector y rotación laboral}

En cuanto a la antigüedad del empleo, puede señalarse que influye en la rotación laboral y es además altamente dependiente de la estructura de edad de la población, pues, el grado de permanencia en una misma empresa aumenta con la edad del trabajador, o dicho de otra manera existe una mayor posibilidad de rotación en la franja etaria de 25 a 35 años que en los cuartiles siguientes.

En ese sentido, al menos dos hipótesis pueden explicar esta aseveración: por una parte, existe una mayor inestabilidad laboral entre los más jóvenes producto de la búsqueda de experiencia en diferentes empresas; por otra parte, se observa que como se produce una entrada más tardía de los jóvenes al mercado laboral por una mayor retención del sistema educativo estos buscan permanentemente obtener experiencia en diferentes empresas. 


\section{Figura 14. Correspondencia entre experiencia en el sector y rotación} laboral

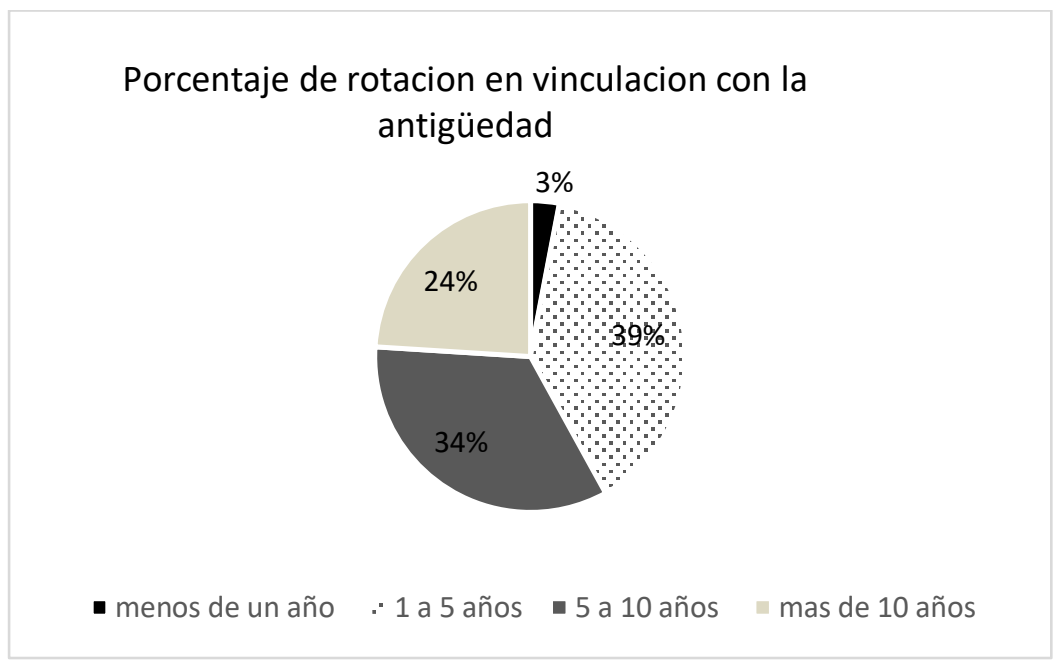

Fuente: elaboración propia sobre la base de datos generados por la encuesta realizada

El comportamiento de la antigüedad promedio cambia de manera esperada al considerar las distintas desagregaciones presentadas. Por ejemplo, se observa que entre el primer y quinto año de incorporación a la vida laboral es donde existe una mayor rotación, dado que en promedio el 39\% de los empleados cambia de empresa de una a tres veces al menos durante esta etapa.

Estos trabajadores, son en un $27 \%$ mujeres y tienen en un $72 \%$ edades que oscilan entre 25 a 35 años. De este modo, se corrobora que los jóvenes en general y las mujeres en particular tienden a cambiar más de trabajo ya sea porque buscan mejores oportunidades o porque están más sujetos a ganar experiencia en diferentes especializaciones.

En tanto, con una antigüedad entre cinco y diez años si bien el grado de rotación es alto va disminuyendo respecto al cuartil anterior, aun así, cuando se produce la rotación, es mayor a tres veces en cinco años. Además, esta franja está compuesta en un $44 \%$ por trabajadores edades de más de 35 años, entre los cuales no hay mujeres.

$\mathrm{Al}$ respecto, debe hacerse la aclaración que en las empresas tecnoinformacionales aquellos trabajadores de mayor edad usualmente tienen mayor permanencia en sus trabajos que los empleados más jóvenes; es decir a una 
edad más avanzada que el promedio, el trabajador tiende a aumentar la antigüedad dentro de una misma empresa. Estos patrones se corroboran también con los porcentajes de trabajadores con un ingreso que crece con retraso respecto a la inflación, y mayores niveles de compromiso familiar. Según lo expresado en una de las entrevistas:

En términos generales, una persona con más de 35 años y más de 10 años de experiencia se le hace muy difícil competir con los chicos que ingresan. Hoy día los chicos programan de una forma distinta. Yo sigo programando y sigo tratando de competir pero las tecnologías que yo manejo de hace diez años contra uno que hace dos años que está en una empresa son diferentes. Si bien nuestro producto está estanco me fortalece esta situación, ahí tengo la experiencia y el conocimiento del negocio. Pero, de no hacerlo, viene un joven nuevo y saca de la galera cosas que vos ni siquiera pensabas, o ni sabias que existían. Sobre todo si uno afloja un poquito a la constante capacitación en tecnología se va quedando. Por eso me recosté en un área que es todo prolijo todo parejo y que sé que no tengo competencia. (EJ, profesional en informática)

Realizándose una ajustada síntesis, puede expresarse que en los diez primeros años de antigüedad laboral se produce una rotación del 58\% del personal, y que las mujeres a pesar de ser menos numéricamente son con relación a los hombres más propensas a realizar la rotación laboral, puesto que en comparación general mientras los hombres rotan en un 50\% las mujeres lo hacen en un $66 \%$.

\subsection{Los desafíos profesionales y las nuevas subjetividades del trabajo}

Los desafíos personales y profesionales se encuentran presentes en los trabajadores informáticos en cuestiones que se vinculan con su trayectoria laboral y la visibilización de un horizonte amplio en la empresa, como también el no reconocimiento de su trabajo y la alienación hacia el mismo. Dichas cuestiones han sido la más votada por hombres, en un $70 \%$, que se encuentran en un rango de edades de 25 a 35 años.

En ambos aspectos, los determinantes se instalan más sobre el plano existencial que sobre el plano económico-material, asumiendo la forma de la frustración subjetiva. Según (Fumagalli, 2010) la frustración subjetiva tiene que ver con la psicología de los individuos en el capitalismo cognitivo. Y si bien, las capacidades intelectuales son hoy dominantes todo individuo requiere de 
motivaciones y de aspectos simbólicos, que van más allá de la racionalidad que impone el mercado.

Paradójicamente, las capacidades relacionales hoy constituyen herramientas laborales, volviéndose instrumentos funcionales al proceso laboral en curso.

La prestación laboral tiende a volverse cada vez más cognitiva y relacional: el cerebro, los sentimientos y la experiencia vital son factores productivos tan importantes, o más, que los brazos o el cuerpo. Las componentes inmateriales crecen mientras el éxito de una mercancía depende cada vez más de los aspectos simbólicos ligados a la misma. (Fumagalli, 2010: 206).

Tal como lo describe el informante clave:

La cultura organizacional y el trato que se le otorga a los recursos humanos es fundamental, el trato humano hace la diferencia. Se trata de dar un espacio a cada persona para que se sienta cómoda y se pueda desenvolver de la mejor forma. Para ello es necesario oficinas abiertas, vinculación con quienes son parte de la gerencia, y respaldo ante una situación problema. (JP, Director de Q4Tech)

A diferencia de conceptos de organización del trabajo anteriores, en este tipo de organización discrecional el sistema de recompensas y castigos no viene impuesto efectivamente por poder disciplinario (Foucault, 2004), es decir, la definición de la relación con el poder está subordinada a la "constitución de sí" como sujeto social, o dicho de otro modo, está mediado por las formas y por el grado de reconocimiento que se le atribuye dentro de las redes de relaciones de trabajo.

Por ello, también podríamos remitirnos a lo conceptualizado por (Honneth, 1997) respecto a la búsqueda de reconocimiento en los individuos. Dicho autor expone la idea que en los vínculos intersubjetivos están inscriptas las señales de la búsqueda de reciprocidad y de reconocimiento. Aquí, la estructura de las relaciones tiene que ver con individuos que se asocian entre sí porque requieren de este otro para desarrollar y confirmar su identidad o para conocer partes de la misma no susceptibles de ser reveladas en el aislamiento. Así, la intersubjetividad es constitutiva de la subjetividad, cumpliendo un rol destacado la experiencia de valoración social que va unida a una seguridad por parte del sujeto en el sentido de poseer capacidades que son reconocidas por otros. 
De este modo, en el capitalismo cognitivo, en el que las subjetividades actúan más en un contexto de cooperación (acción), el individuo es social en términos económicos, y las relaciones sociales con el otro en muchos casos tienden a transformarse en competitividad alienante, y por ello se deben promover las acciones que lo impidan.

Una segunda cuestión, se encuentra en la importancia que se le otorga a los desafíos profesionales. Tal y como lo señala uno de los informantes consultados:

Muchas veces las personas van en busca de un puesto donde pueda ejercer un rol que le guste, y no va solo en la tecnología, también en el papel que desempeña en la empresa, hay personas que por ejemplo que les gusta ser líder y coordinar gente, y a lo mejor donde esta no tiene la posibilidad y encuentra una oferta en esa posición y decide irse. Otras razones pasan mucho por los productos de la empresa, puede darse que están hechos en ciertas tecnologías y no cambian de tecnología muy a menudo, y eso hace sentir a las personas como estancadas en la misma tecnología por años, y se quiere trabajar en otras tecnologías y salen a buscar en el mercado otra oferta más acorde. (JR, AGC Tandil)

El mismo proceso de individualización, característico de la esfera tecnoinformacional, contiene también en su interior la idea emancipadora del individuo respecto de la determinación adscrita, heredada o innata de su carácter social, y lo deja abierto a la aventura y realización individual.

Lo cierto, es que la búsqueda de nichos o espacios de identificación a los que los individuos pueden tener acceso y en los cuales pueden desear establecerse, difícilmente pueden adecuarse a objetivos del tipo "proyectos de vida". Dado que la transitoriedad es el signo permanente de la vida actual con sus estados de inseguridad, incertidumbre y riesgo asociados.

\section{Conclusiones}

Por lo expuesto, la rotación laboral no constituye solo un suceso, tras de ella se encuentran una serie de hechos correlacionados. Por ello en el transcurso del presente estudio, se ha realizado el análisis de algunos posibles indicadores que nos pueden colaborar para entender los motivos por los que se produce. 
Dicho análisis, estuvo enmarcado en las 50 empresas que conformaron en el periodo de estudio la Cámara de Empresas del Polo Informático Tandil, bajo un relevamiento de 46 empleados pertenecientes a las mismas.

Específicamente, nuestra visión se ha enfocado a la rotación laboral como proceso, y allí podemos observar que la misma es producto de un complejo entrelazamiento de variables individuales.

Una de ellas, se encuentra en las características propias de los trabajadores del sector tecno-informacional. La primera observación, es que la composición de la fuerza laboral, es mayoritariamente masculina. Aquí intervienen cuestiones que se vinculan a la formación así como la perspectiva sobre ciertas competencias del rubro en ambos sexos que constituyen una cuestión más vinculada a parámetros sociales que reales.

También, se debe tener presente la participación de la mujer en el mercado al momento de analizar la muestra y correlacionarlo con la franja etaria de la población que mayoritariamente se encuentra en el rango de 25 a 40 años. Tradicionalmente, las mujeres tienden en ese periodo a permanecer un tiempo fuera del mercado de trabajo, o en otros casos a disminuir su participación, por cuestiones familiares relacionadas con el cuidado de los hijos, o bien tienden a emplearse en el ámbito estatal donde se les otorga permanencia en el puesto y convenciones colectivas de trabajo.

Por otra parte, encontramos que el rango de edades de los trabajadores se establece mayoritariamente entre los 25 y 40 años. Esta tendencia deja en evidencia la reducción del período en el cual los agentes permanecen en el mercado. Y además, el análisis de estas edades mayoritarias en la población nos conduce a pensar que la flexibilización no solo se produce en la organización de la producción, sino también se vuelve un principio que transversaliza todas las relaciones, desde la contratación laboral hasta el perfil de edades que se elige para ocupar los puestos de trabajo, dado que se buscan las edades en las cuales las personas tienden a adecuarse más rápidamente a las transformaciones del mercado y la empresa.

Desde la perspectiva de los trabajadores en esa franja, podría señalarse que los mismos tienen como objetivo ganar experiencia en tecnologías y en diversas formas de trabajo, quizás por ello, es el momento de la trayectoria laboral individual donde se asiste a una mayor rotación.

En contraposición, en las personas mayores de 40 años la responsabilidad ante el empleo es otra, los candidatos buscan mayor estabilidad laboral, valoran trabajar en una empresa que les otorguen salario en blanco y obra social. Esta 
situación, se adapta mejor para posiciones senior con alto nivel de exposición, aun así, a la hora de contratar a un persona de esta edad, la clave es la cultura de la compañía.

En tanto, en el comportamiento de la antigüedad se ha observado que entre el primer y quinto año de incorporación a la vida laboral es donde existe una mayor rotación, y que en promedio los trabajadores cambian de empresa de una a tres veces al menos durante esta etapa.

Otra serie de cuestiones se vincula a los motivos que inducen a la rotación, se habla en plural porque la elección de los encuestados marca claramente que se constituye un grupo de razones entre las que sobresalen la cuestión salarial y motivos vinculados con las subjetividades laborales.

Con respecto al salario, existen dos materias que influyen en su determinación; por una parte y visto desde la perspectiva empresarial las variables macro y microeconómicas confluyen en una posible estimación del monto de los costos salariales y los beneficios que se desea obtener.

En tanto, desde la faz del trabajador hay tres temas que se entrecruzan: por una parte, la experiencia en el sector, que indica el grado de habilidad del mismo para afrontar los problemas tecnológicos o para resolver las situacionesproblemas planteadas en los proyectos. En segundo lugar, encontramos el rol que cumple la capacitación continua y la proactividad del trabajador para el aprendizaje de nuevas tecnologías, ello incluye la búsqueda de capacitación permanente más allá de las posibilidades otorgadas por la empresa.

$\mathrm{Y}$ en tercer término, su poder de negociación pues las personas dedicadas al campo de la informática sintetizan la figura del asalariado y la del empresario. Específicamente, en estos casos confluye el hecho que su remuneración es estrictamente dependiente de la autoexplotación de su propia capacidad de trabajo, por tanto el monto final de la negociación es el número definitivo del sueldo. Aun así, a este tema se adiciona la evaluación individual de desempeño, que según el rendimiento, puede conducir a un aumento en la percepción.

Con la finalidad de disminuir la rotación de personal, y bajo la visión de complementar el pago salarial, las empresas ponen en práctica estrategias entre las que se cuentan: pagos no remunerativos que se traducen en beneficios otorgados, como también en sistemas de capacitación, u otras opciones no dinerarias como tiempo de cumplimiento de la tarea fuera de la empresa, e incentivos de carrera en las trayectorias individuales, entre otros.

En realidad, no todos estos mecanismos contienen el mismo grado de efectividad. Si bien las prestaciones adicionales son las más aceptadas, dado que 
el mayor porcentaje de rotación se encuentra en aquellos que no perciben beneficios; no sucede lo mismo cuando se habla de home-office, pues el estímulo hacia la flexibilidad horaria a partir de la domesticación laboral no necesariamente constituye un mecanismo suficiente para la retención.

De otra parte, encontramos los motivos vinculados con la subjetividad laboral, o dicho de otra forma con los desafíos personales y profesionales se encuentran presentes en los trabajadores informáticos en cuestiones que se vinculan con su trayectoria laboral y la visibilización de un horizonte amplio en la empresa, o bien del no reconocimiento de su trabajo y la alienación hacia el mismo.

En este caso, los determinantes se instalan más sobre el plano existencial que sobre el plano económico-material, asumiendo la forma de la frustración subjetiva, pues más allá del desarrollo del perfil, la contención dentro del ámbito laboral y el reconocimiento o valoración sobre su trabajo constituyen cuestiones importantes; hay que recordar que los sentimientos y la experiencia vital son factores productivos tan importantes, o más, que las capacidades contenidas.

En síntesis, ¿cuáles son los perfiles que se hallan en los extremos?, o dicho en otras palabras ¿cuáles son las características más destacables tanto que aquellos trabajadores que tienden a rotar como de quienes rotan menos?

Quienes son los más proclives a rotar con relación a la variable identificación de género son las mujeres que rotan en un $66 \%$ mientras que los hombres lo hacen en un $58 \%$. En cuanto a las edades, la rotación se produce más en la franja etaria de 25 a 35 años, que tienen una antigüedad en el sector de 5 a 10 años.

Respecto a la cantidad de veces que rotan cada cinco años se encuentra en el orden de 1 y 3 veces, o equivalente a una rotación cada año y medio. En general, no existe un motivo específico, siempre se presentan como un conjunto de motivos en donde los desafíos personales y la cuestión salarial tienen un peso importante, no adquiriendo la misma valoración el trabajo in bouse, ni la capacitación laboral.

En tanto, quienes rotan menos son los hombres que tienen edad entre 35 y 40 años aunque no tengan beneficios extraordinarios, capacitación promovida por la empresa, ni home-office, con más de 10 años de antigüedad laboral en el sector. 


\section{Referencias}

Bauman, Z. (2003). La Modernidad Liquida. Mexico: Fondo de cultura economica.

Borello, J; Erbes, A; Robert, V; Roitter, G; y Yoguel, G. (2005). Competencias técnicas de los trabajadores informáticos. El caso de la Argentina. Revista de la CEPAL, 87, 131-150.

Borrastero, C; y Motta, J. (2011). El sector Software y Servicios Informáticos de Córdoba: principales características y desempeño reciente. Actualidad Económica, 21 (75), 23-37.

Boscherini, F; Novick, M; y Yoguel, G. (2003). Nuevas tecnologías de información y comunicación. Los límites en la economía del conocimiento. Madrid: Miño y Dávila.

Blondeau, O. (1999). Génesis y subversión del capitalismo informacional. En: Rodríguez, E y Sánchez, R (Comp.). (31-38). Capitalismo cognitivo, propiedad intelectualy creación colectiva. Madrid: Traficantes de Sueños.

Boutang, Y. (1999). Riqueza, propiedad, libertad y renta en el capitalismo cognitivo. En: Rodríguez, E y Sánchez, R (Comp.). (107-120). Capitalismo cognitivo, propiedad intelectualy creación colectiva. Madrid: Traficantes de Sueños

Castells, M. (2006). La era de la información. Tomo 1. México: Siglo XXI.

Coriat, B. (1998). El tallery el cronómetro. México: Siglo XXI.

Chudnovsky, D; López, A; y Melitzco, S. (2001). El sector de software y servicios informáticos en la Argentina. Situación actual y perspectivas de desarrollo. Documento de trabajo. núm. 27. Centro de Investigaciones para la Transformación.

Corsani, A. (2003). La hipótesis del capitalismo cognitivo. En: Giusseppe Cocco, A. Patez Galvao, G. Capitalismo Cognitivo. Río de Janeiro: DP\&A.

Dessler, G; y Varela Juárez, R. (1996). Administración de Recursos Humanos. Enfoque latinoamericano. México: Prentice Hall

Foucault, M. (2004). Vigilary Castigar. Buenos Aires: Siglo XX

Fumagalli, A. (2010). Bioeconomía y capitalismo cognitivo. Madrid: Traficantes de Sueños.

Honneth, A. (1997). La lucha por el reconocimiento. Por una gramática moral de los conflictos sociales. Barcelona: Crítica.

Khun, T. (1971). La estructura de las revoluciones cientificas. México: Fondo de Cultura Económica.

Lazzarato, M; y Negri, A. (2001). El trabajo inmaterial. Formas de vida y producción de subjetividad. Río de Janeiro: DP\&A editora. 
Lopez Bidone, E. (2014). El proceso de innovación tecnológico y la localización de las actividades productivas: El Parque Tecnológico de la Universidad nacional del Centro de la Provincia de Buenos Aires como caso de Estudio (2003-2007). En Serie Investigaciones III. (155-177). Recuperado de: www. http://plazapublica.fch.unicen.edu.ar/images/stories/noticias/201507/SERIE_INVESTIGACIONES01_08-09-2015.pdf

Lundvall, B. (2006). Innovation System Research and Policy Where it came from and where it might go. Oslo: CAS Seminar.

Novick, M. (2008). Desarrollo e innovación: un debate en torno a la revalorización del trabajo. Revista del trabajo, 4 (5), 49- 61.

Rabosto, A; y Zukerfeld, M. (2019) El sector argentino de software: desacoples entre empleo, salarios y educación. Ciencia, Tecnología y Política, 2 (2), 26-35.

Rodríguez Fernández, A. (1998). Introducción a la psicología del trabajo y de las organizaciones. Madrid: Editorial Pirámide.

Rullani, E. (2000). El capitalismo cognitivo ¿un déjà- vu? En: Rodríguez, E y Sánchez, R. (Comp.).(99-106). Capitalismo cognitivo, propiedad intelectual y creación colectiva. Madrid: Traficantes de Sueños.

Vercellone, C. (2000). Las políticas de desarrollo en tiempos del capitalismo cognitivo. En: Rodríguez, E y Sánchez, R. (Comp.). (63-70). Capitalismo cognitivo, propiedad intelectual y creación colectiva. Madrid: Traficantes de Sueños.

Zukerfeld, M. (2008). Capitalismo cognitivo, trabajo informacional y algo de música. Revista Nómadas, 28, 52-65.

Zukerfeld, M. (2010). Capitalismo y conocimiento: materialismo cognitivo, propiedad intelectual y capitalismo informacional. Vol. 3. Capitalismo y Conocimiento. Recuperado de: http://capitalismoyconocimiento.

Zukerfeld, M. (2010). Cinco hipótesis sobre el trabajo informacional. Revista Gestión de Personas y Tecnologia, 9, 76-85.

Zukerfeld, M; Botta, M; Dughera, L; y Yansen, G. (2013). Y las mujeres.... ¿Dónde están? Primer estudio de la Fundación Dr. Manuel Sadosky sobre la baja presencia femenina en informática. Fundación Sadosky. Recuperado de: $\quad$ http://www.fundacionsadosky.org.ar/wpcontent/uploads/2015/05/resumen-mujeres-y-computacion-2013.pdf

Zukerfeld, M. (2015). La tecnología en general, las digitales en particular. Vida, milagros y familia de la "Ley de Moore". Hipertextos, 2 (4). 